\title{
Understanding How Co-op Students View their Learning
}

\section{Ms. Katherine M Ehlert, Clemson University}

Katherine M. Ehlert is a doctoral student in the Engineering and Science Education department in the College of Engineering, Computing, and Applied Sciences at Clemson University. She earned her BS in Mechanical Engineering from Case Western Reserve University and her MS in Mechanical Engineering focusing on Biomechanics from Cornell University. Prior to her enrollment at Clemson, Katherine worked as a Biomedical Engineering consultant in Philadelphia, PA. Her research interests include identity development through research experiences for engineering students, student pathways to engineering degree completion, and documenting the influence of co-op experiences on academic performance.

\section{Dr. Marisa K. Orr, Clemson University}

Marisa K. Orr is an Assistant Professor in Engineering and Science Education with a joint appointment in the Department of Mechanical Engineering at Clemson University. Her research interests include student persistence and pathways in engineering, gender equity, diversity, and academic policy. Dr. Orr is a recipient of the NSF CAREER Award for her research entitled, "Empowering Students to be Adaptive Decision-Makers." 


\title{
Understanding How Co-op Students View their Learning
}

\begin{abstract}
This research paper discusses student perspectives on learning while on co-op and suggests ways to improve co-op experiences for students. Successful outcomes of co-op, like graduating with higher GPAs [1], [2], having an easier time transitioning into full-time work [3], or beginning with higher starting salaries [2], [4] have been discussed in the past, however, little is formally documented on the ways in which co-op provides these benefits. These benefits could be realized through many different pathways which may include students improving technical and/or professional skills, refining their identity, and increasing their self-efficacy, among others. The purpose of this embedded mixed-methods study was to document student perceptions of learning while on co-op and provide student-centered language for these learning experiences.
\end{abstract}

\section{Introduction}

There is a high demand for well-trained engineers that can create innovative solutions to complex world problems [5]-[9]. To solve the National Academy of Engineers Grand Challenges [6] or other engineering problems of today, we need the current and next generation of engineers to quickly transition into their full-time roles, work efficiently and respectfully with others on a multidisciplinary team, be comfortable with large-scale, open-ended problems, and have a strong understanding of fundamental material that they can map to new problems in the workplace. However, engineering students struggle in transitioning into full-time work [10][13]. When asked why they were struggling, students expressed that they did not expect the variety or complexity of the problems they were facing as engineers [10]. They felt unprepared [10] and that previous work experience was the only way to build the skills necessary to solve these problems [13]. This struggle to transition into full-time work could be related to the differences in what knowledge, skills, or abilities are valued in an engineering curriculum over industry [10], [12], [13]. To combat this struggle, academia can provide students opportunities for work or work-like experiences throughout the curriculum.

One such way to provide work experiences to students is through cooperative education (co-op). Co-op has many documented benefits including academic, professional, and financial. Students who co-op tend to earn better grades than their non-co-op peers in upper-level classes [14], graduate with higher GPAs [1], [2], take jobs in the same field [15], have an easier time transitioning to full-time work [3], have higher career self-efficacy [16]-[18], and earn higher starting salaries [2], [4]. While these studies show the valuable outcomes of co-op experiences, few studies have been able to document what is learned in these work experiences. Documenting learning on co-op can be difficult because of the variety of experiences that a student may have while on co-op.

Johnston, Angerilli, and Gajdamaschko [19] were able to begin documenting perceptions of learning while on co-op and they explored how those views differed between students and practitioners at 2- and 4-year institutions in British Columbia. Johnston et al. documented eight different groups, six predominately student views and two predominately practitioner views. 
Most students saw co-op as a place for one of the following: (1) building technical skills, (2) building effective communication and workplace skills, (3) learning about their intended field and themselves as they integrate into the workplace, (4) understanding how to apply content learned in school in the real world, and (5) augmenting their knowledge from school with additional or deeper content. The last group felt that any relevant work experience would be valuable, regardless of if that work experience was formalized through a co-op program. The breadth of the programs and participants in the Johnston et al. study limits what claims could be made to the student perspective or identify specific practices that can help students learn the most from these experiences. The purpose of the present study is to document student perceptions of learning on co-op with the intent to develop language that can help students glean the most from their co-op experiences. The specific research question we seek to answer is "What are the different ways students perceive learning on their co-op?"

\section{Methods}

\section{Q-Methodology}

Student perceptions of learning were documented using the Q-Methodology (or Q for short) which systematically groups participants based on their viewpoints [20], [21]. Q has been used across disciplines to group participants [21] as well as within engineering education [22]. In a $Q$ study, participants take a set of statements developed by the researcher that represent the breadth of opinions about the subject and sort those statements along a continuum from Strongly Disagree to Strongly Agree in a quasi-normal distribution (Figure 1). After participants complete the sorting exercise, numerical values were attributed to each statement. Participants are then grouped together based on how well they correlate with each other. After groups have been established, descriptions of those grouped are developed based on how participants ranked different statements.

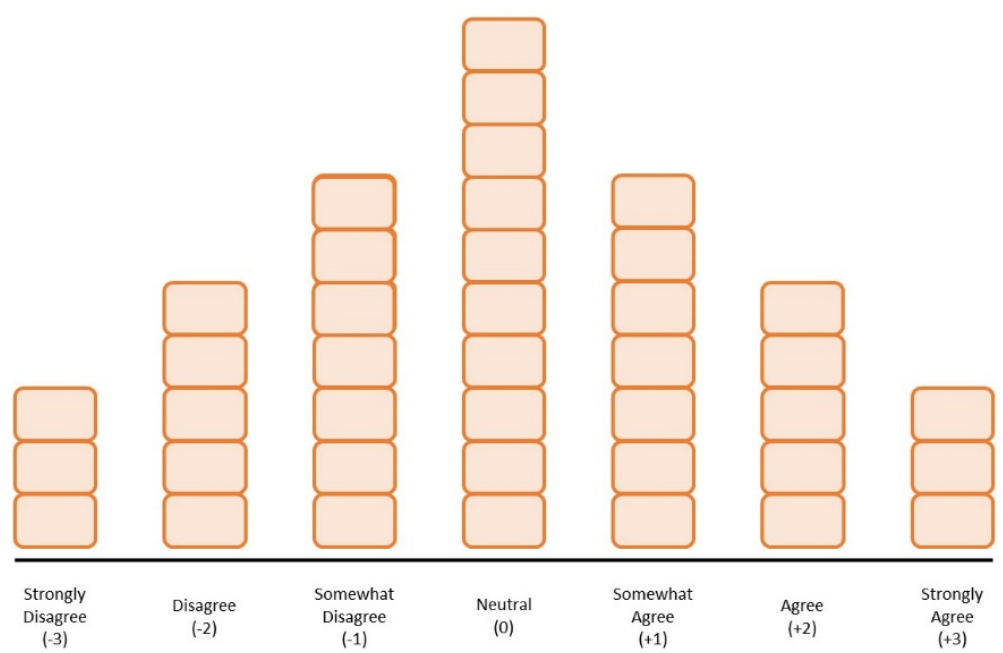

Figure 1. Visual of the quasi-normal distribution used in the sorting exercise. 
In this study, participants were asked to sort 42 statements related to learning on co-op.

Statements connected specific skills ("to work as a part of a team", "to find and solve problems", "what to expect as an engineer", "the technical skills of my discipline", etc.) and how that learning could occur ("by watching the engineers in my company and doing what they do", "from my own successes and failures", "after gaining responsibilities and becoming more integrated into the workplace", etc.).

\section{Data Collection}

Data was collected at a single, public institution in the southeast United States in the Spring of 2019. An email was distributed to all students enrolled in the institution's co-op course in the Fall of 2018 to participate in a short survey asking about their co-op experiences, demographic information, and their interest in participating in a follow-up interview. A total of 53 unique students participated in the survey. Those interested in participating in the interview were invited to schedule a time at their convenience with the interviewer. Twenty-eight students participated in the interview where they sorted the developed statements related to learning on co-op and then were asked to describe their views in more detail.

The sorting process took approximately 10 - 15 minutes for students to complete with an additional $30-45$ minutes for the interview. Interview questions centered around asking students why they choose to place the statements where they were placed, what parts of their work experiences could they relate to the statements, and whether aspects of their experiences were missing from the statements.

\section{Data Analysis}

After all the participants completed the interviews, scores as depicted in Figure 1 were applied to the statements relative to each participant's sort. Statistical analysis was conducted using the qmethod package in R Statistical Software [23]. The results of the quantitative analysis indicated that multiple grouping solutions were viable. Each solution was explored qualitatively to first discern the appropriate number of groups and then develop descriptions of each group. Qualitative analysis included the review of each members sorting results, the statements ranked the highest and lowest by the group, interview notes, and the interview transcript.

\section{Results}

Initial quantitative analysis suggested that three to six groups existed in the data. To determine the appropriate number of groups, representative sorts were developed for each group. These representative sorts were an average of all the sorts of the members within the group and are a reasonable representation of the group view. After each representative sort was developed for each group, sorts were compared to determine if they were qualitatively different from one another. If no substantial qualitative difference could be developed, the solution was removed from consideration. After review of all the viable solutions, we determined the most reasonable solution comprised of four unique groups. After the four-group solution was selected, the representative sorts, distinguishing statements, and interview data were used to develop the group profile. 
There were some overall trends in the data. First, the specific co-op role and the daily responsibilities heavily influenced student views on learning. Students who were working as integral part of a team ranked statements related to teamwork higher than those who were operating more independently. The influence of role on learning is to be expected as learning is often context specific.

Additionally, many of the participants disagreed with statements that included the phrase "when I reflected and thought about my learning". Students interpreted "reflection" to be the process of writing a reflection and thinking about their holistic experience instead of the intended interpretation of thinking about an observation in real time. One exception was the statement "On co-op, I learned more about what I really want to do with my career when I reflected and thought about my learning." This was the highest scored reflection statement, and one that was pivotal to the Decider group described below.

Lastly, not a single student expressed regret for participating in the co-op experience, although some did not enjoy their co-op. Many of the participants stated that the co-op was the most impactful experience of their collegiate career and would recommend co-op to any student.

The four groups were named (1) The Problem Solvers, (2) The Team Players, (3) The Doers, and (4) The Deciders and are described in detail below. Although each group has unique viewpoints, that does not necessarily mean that the views of one group are mutually exclusive from the others, just that these were the predominate views of the group.

\section{The Problem Solvers}

These students rated statements relating to "finding and solving problems" very high. Students in this group had daily responsibilities that required them to find and solve problems. This group consisted of students who were in roles like software development, failure analysis, or quality control. Additionally, students ranked statements including "On co-op, I learned new skills that will help me be successful in the workplace" high. They expressed that there were specific skills that had not been developed in school that they built out in their co-op experience. For software developers, it was object-oriented programming. For other students, it was understanding the quality system at their company and how to communicate with others in the plant. Students in this group, however, did not believe they learned by "watching the engineers and doing what they do". They expressed that they were less likely to learn something if it was done for them. Additionally, these students disagreed with the statement that they learned "how much I don't know. Students express that the entered the co-op already knowing they were going to not know everything and were open to gaining knowledge from this experience.

\section{The Team Players}

While the Problem Solvers tended to be independent, or feel they had little need to report their work progress beyond their immediate mentor, the Team Players knew their role was as an integral part of a team. These students ranked statements related to "learning how to work as a part of a team" very high as well as "to communicate effectively with others". Students in this group saw that if they could not complete their assigned tasks, it would be at the detriment of their department or the company. These students were in roles that looked at improving the manufacturing process and reducing the waste in the manufacturing process. Unlike the Problem 
Solvers, this group valued learning from the engineers and doing what they did. They saw engineers as an important resource to learn how to interact with others so they could be more effective at their jobs. However, students in this group felt they were not able to build conflict management skills well. They did not experience many conflicts first-hand and therefore felt they did not develop skills to manage conflicts "by repeated practice in real-world situations" or "through my own successes and failures."

\section{The Doers}

For these students, learning occurred through the act of doing. Unlike the Problem Solvers and the Team Players, students in this group felt they learned a variety of skills through doing them. Students in this group rated statements that described learning through "gaining responsibilities and becoming more integrated into the workplace" and through "repeated practice in real-world situations" very high. These students described building communication skills, new skills that would help in their workplace, and how to manage conflicts by participating in the process. Statements they ranked low were related to building "technical skills of my discipline" and "how much I really don't know." Overall, these students believed that technical skills were developed in the classroom or using textbooks whereas skills that would help them in the workplace were ones that helped them develop relationships with people or how to navigate the workplace.

\section{The Deciders}

Students in this group described learning more about themselves rather than building skills or learning through doing. The highest rated statement for these students was "On co-op, I learned more about what I really want to do with my career when I reflected on my co-op experiences and thought about my learning." They also rated many of the other statements relating to learning "more about what I really want to do with my career" and learning by "watching the engineers and doing what they do" very high. Students in this group saw co-op as an opportunity to try out a discipline-specific job before making a more long-term commitment to a company after graduation. Many of the students in this group did not enjoy their day-to-day responsibilities nor the responsibilities of other engineers in different roles when they observed them. These students found what they had imagined their disciplinary work to be was very different than what it was and did not enjoy it. Students expressed a significant appreciation for the co-op experience, however, stating that they were able to adjust their coursework before it was "too late". One student majoring in mechanical engineering, did not enjoy most of their work, but the last few weeks of their co-op, they were asked to develop some computational models which they found quite enjoyable. After returning to class, this student is now minoring in physics and is seeking a master's degree so they can pursue a career focused on modeling and optimization. Of all the groups, these students recommended co-op the most as they felt they had prevented future dissatisfaction. By being able to work and see how work was for their profession, students felt more confident in their career choices moving forward.

Each group of students found specific benefits from co-op that map well to the documented benefits. Problem Solvers may approach their classes differently and are more comfortable solving problems in their advanced classes relative to their non-co-op peers. Team Players could be more likely to transition faster as they have the skills to observe what others do and know how to contribute to the success of a company. Doers may be more likely to have a higher starting 
salary because they have a wide variety of developed skills. Deciders might have higher career self-efficacy because they are more confident in their ability to succeed in their future careers.

\section{Discussion}

Ideally, the co-op experience would provide each of these four learning experiences. Students should have opportunities to build problem-solving skills (especially skills in finding and defining a problem), team skills and the understanding how their work (or lack thereof) impacts the success of a team, to learn through doing and practicing their profession, and to be able to make appropriate career decisions to ensure professional satisfaction. To help guide the co-op experience, administrators should work with industry representatives to build rotations that foster each part of the experience throughout co-op rotations. For example, one co-op rotation could assign a student to team-oriented experience so that they build team skills and then the next coop rotation could focus more on problem-solving responsibilities. Guiding companies to scaffold co-op experiences can help improve the co-op experience for both the company and the student.

On the student side, administrators can help guide student expectations using these group descriptions. If a student only focuses on building team skills or making a career decision, they could be missing out on other benefits the co-op provides. By giving students these group descriptions up front, they could be more open to all that co-op has to offer. Knowing this information prior to beginning their co-op, students could be better prepared for their role and might be more motivated to complete multiple rotations.

\section{Future Work}

Future work is to expand this data beyond a single institution to look for other contextual influences on student views. This will help build better descriptions or find additional unique groups. Additionally, this expanded work can help identify how institutional or corporate cultures could be impacting the co-op experience.

\section{References}

[1] R. S. Lindenmeyer, "A comparison study of the academic progress of the cooperative and the four year student," J. Coop. Educ., vol. 3, no. 2, pp. 8-18, 1967.

[2] B. F. Blair, M. Millea, and J. Hammer, "The Impact of Cooperative Education on Academic Performance and Compensation of Engieering Majors," J. Eng. Educ., vol. 93, no. 4, pp. 333-338, 2004.

[3] P. Gardner and S. W. J. Koslowski, "Learning the ropes: co-ops do it faster," J. Coop. Educ. Internships, vol. 28, no. 3, pp. 30-41, 1993.

[4] P. D. Gardner, D. C. Nixon, and G. Motschenbacher, "Starting salary outcomes of cooperative education graduates," J. Coop. Educ. Internships, vol. 27, no. 3, pp. 16-26, 1992.

[5] G. W. Clough, "The engineer of 2020 : visions of engineering in the new century," Washington, D. C., 2004.

[6] National Academy of Engineering, "National Academy of Engineering Grand Challenges For Engineers," pp. 19-22, 2017.

[7] J. J. Duderstadt, "Engineering for a Changing World A Roadmap to the Future of A Roadmap to the Future of," Engineering, p. 131, 2008.

[8] J. J. Duderstadt, “A Flexner Report for Engineering: The Future of Engineering Practice, 
Research, and Education,” pp. 1-16, 2016.

[9] ABET, "Lessons from Leaders on Modernizing Higher Education Engineering Curriculum Engineering Change," 2017.

[10] M. Clark, S. D. Sheppard, C. J. Atman, L. N. Fleming, and R. L. Miller, "Academic Pathways Study : Processes and Realities," Chart, 2008.

[11] J. L. Huff, C. B. Zoltowski, and W. C. Oakes, "Preparing Engineers for the Workplace through Service Learning: Perceptions of EPICS Alumni," J. Eng. Educ., vol. 105, no. 1, pp. 43-69, 2016.

[12] C. A. Carrico, K. E. Winters, S. Brunhaver, and H. M. Matusovich, "The Pathways Taken by Early Career Professionals and the Factors that Contribute to Pathway Choices," Proc. 2012 Am. Soc. Eng. Educ. Annu. Conf. Expo., 2012.

[13] S. R. Brunhaver, R. F. Korte, S. R. Barley, and S. D. Sheppard, "Bridging the gaps between engineering education and practice," in US Engineering in a Global Economy, R. B. Freeman and H. Salzman, Eds. Chicago, Il: University of Chicago Press, 2018, pp. 129-163.

[14] C. R. Noyes, J. Gordon, and J. Ludlum, "The Academic Effects of Cooperative Education Experiences: Does Co-op Make a Difference in Engineering Coursework?," in American Society for Engineering Education Annual Conference \& Exposition, 2011.

[15] P. L. Linn, J. Ferguson, and K. Egart, "Career exploration via cooperative education and lifespan occupational choice," J. Vocat. Behav., vol. 65, no. 3, pp. 430-447, 2004.

[16] J. Raelin, R. Reisberg, D. Whitman, and J. Hamann, "Cooperative education as a means to enhance self-efficacy among sophomores (with particular attention to women) in undergraduate engineering," Proc. - Front. Educ. Conf. FIE, pp. 20-24, 2007.

[17] R. Reisberg, J. A. Raelin, M. B. Bailey, D. L. Whitman, J. C. Hamann, and L. K. Pendleton, "The Effect of Cooperative Education on the Self-Efficacy of Students in Undergraduate Engineering," in American Society for Engineering Education Annual Conference \& Exposition, 2012.

[18] J. A. Raelin, M. B. Bailey, J. C. Hamann, D. L. Whitman, R. Reisberg, and L. K. Pendleton, "The effect of cooperative education and contextual support on the retention of undergraduate engineering students," ASEE Annu. Conf. Expo. Conf. Proc., 2014.

[19] N. Johnston, N. Angerilli, and N. Gajdamaschko, "How to Measure Complex Learning Processes : The Nature of Learning in Cooperative Education," in The Handbook for Research in Cooperative Education and Internships, 1st ed., P. L. Linn, A. Howard, and E. Miller, Eds. Routledge, 2003, pp. 157-187.

[20] S. R. Brown, Political Subjectivity. 1980.

[21] S. R. Brown, "A primer on Q methodology," Operant Subj., vol. 16, no. 3/4, pp. 91-138, 1993.

[22] R. L. Kajfez, C. M. Croyle, A. N. Snyder, and M. J. Mohammadi-Aragh, "Engineering education Ph.D. Students: Where are they now and what was the job search process like?," ASEE Annu. Conf. Expo. Conf. Proc., 2014.

[23] R. C. Team, "R: A language and environment for statistical computing." R Foundation for Statistical Computing, Vienna, Austria, 2016. 